\title{
28. COMMISSION DES NÉBULEUSES ET DES AMAS STELLAIRES
}

\author{
Président: M. Shapley, Director of the Harvard College Observatory, Cambridge, \\ Mass., U.S.A. \\ MEMBREs: MM. Baade, Bernheimer, Carpenter, Hogg, Hubble, Humason, Jeans, \\ Lampland, Lemaître, Lundmark, Madwar, Paraskévopoulos, Parvulesco, \\ Reinmuth, Reynolds, Mme Roberts, MM. V. M. Slipher, Trumpler, Vander- \\ linden, Van Maanen, Von Zeipel, Wirtz, W. H. Wright.
}

I. Since the field covered by Commission No. 28 extends over the problems of three very different types of objects - external galaxies, galactic nebulae, and star clusters-it has been proposed occasionally that the Commission might well be subdivided, or possibly eventually split into three separate Commissions. As Trumpler points out, these three fields "have often been grouped together... more on a historical basis than on an actual similarity of the researches... which are more and more drifting apart." But some members of the Commission have noted that a distinct difference also separates globular clusters and galactic clusters; and that planetary nebulae and dark absorbing clouds involve at times widely different types of investigations. The chairman of the Commission has made a canvass of the opinions of the members and finds that a large majority believe that no division or subdivision is advisable at this time. It is suggested that the organization or reorganization of a Commission should be left to the Union as a whole or to the Executive Committee.

In order that some special phases of the general study of nebulae and star clusters be not neglected, it is suggested that at the forthcoming meetings of the Commission in Paris the subjects for discussion include:

(a) Problems of nebular spectrophotometry (in conjunction with Commission 36).

(b) Problems of dark nebulae and Hagen's Fields.

2. Commendable activity in the story of nebulae during the past year can be reported. Dr Lundmark's very full survey of the field for the I932 report of the Commission makes it unnecessary to go again into general details. In the present report several outstanding investigations will be mentioned with emphasis on those that are of co-operative interest.

The publication in I933 of the chapter on Nebulae by Dr H. D. Curtis in the Handbuch der Astrophysik was an important event for students of the subject. Dr Lundmark reports steady progress on the Lund General Catalogue (see I932 report, p. I72). Progress on the general survey for faint galaxies in both northern and southern hemispheres is reported by Shapley in the Darwin Lecture (Monthly Notices, 94, 79I, 1934). The total number of discovered but unpublished nebulae marked on Harvard plates up to March I, I935, is approximately I40,000, most of which are fainter than the sixteenth magnitude. Supplementing the systematic work with the 24-inch Bruce refractor at Bloemfontein, the Metcalf I6-inch refractor of the Harvard Observatory at the Oak Ridge Station has been steadily employed for the past year in a systematic survey of the northern sky.

Dr Hubble's great survey of nebulae to fainter than the nineteenth magnitude in 1283 selected areas has been published and discussed in detail in Mount Wilson Contribution, 485, 1934. Dr Mayall at the Lick Observatory has published a survey of nebulae appearing on plates made with the Crossley reflector (L.O.B. 458, I934). Dr Carpenter, of the Steward Observatory, Tucson, has essentially completed a 
survey of the individual nebulae to approximately the fourteenth magnitude in the zone of declination $+I 5^{\circ}$ to $+30^{\circ}$. Dr Keenan at the Yerkes Observatory has begun the comparable survey for nebulae north of declination $+50^{\circ}$. The brighter objects south of declination $-60^{\circ}$ photographed with the Bruce telescope are under study at the Harvard Observatory. Other information concerning this co-operative work, begun approximately ten years ago, is not available.

With a Schraffierkassette and the ro-inch refractor at the Mount Wilson Observatory, $\mathrm{Mr}$ Christie has begun a photometric survey of all extragalactic nebulae, in Harvard Annals, 88, No. 2, north of declination $-15^{\circ}$. He has already completed observations with this apparatus on all globular clusters that are easily obtainable at Mount Wilson. The magnitude scale of the Shapley and Ames catalogue (H.A. 88, No. 2) has been investigated by Mr Carl Seyfert at the Harvard Observatory, who has used a Schilt microphotometer to measure the out-of-focus images obtained with various cameras (Harv. Cir., in press). He finds no correction to the zero point and scale of the earlier determinations of magnitude between magnitude $I I \cdot 0$ and 13.3; but discrepancies between the two methods appear for the relatively few objects brighter than the eleventh magnitude. Similar checking of these magnitudes has been undertaken by Dr Redman at the Solar Physics Laboratory, Cambridge, and by $\mathrm{Mr}$ Keenan at the Yerkes Observatory.

Miss Mohr and assistants have inaugurated a "fifteenth magnitude survey" which will eventually provide the integrated photographic magnitudes, the positions, angular diameters, and classification of more than ten thousand galaxies fainter than the thirteenth magnitude. The survey is to supplement on a uniform basis the earlier "thirteenth magnitude survey" in Harvard Annals, 88, No. 2. Cameras with lenses designed by Dr F. E. Ross are used at both northern and southern stations for this work. Photographs of intermediate exposure lengths with the larger telescopes are used for the discovery and description of the objects. Initially the survey will deal with large selected regions, and ultimately cover the whole sky to photographic magnitude fifteen.

Dr Madwar of Helwan hopes to present at the Paris meeting of the Union a final list of nebulae photographed at Helwan in declinations $0^{\circ}$ to $-40^{\circ}$.

3. In all surveys of the numbers and magnitudes of faint nebulae, the problem of magnitude standards is most important. Several members of the Commission emphasize the need of further work on faint magnitude sequences, and especially on the verification and extension of tables relating the number of stars per square degree to galactic co-ordinates and photographic magnitudes. The star-count method has become effective and efficient in the survey of metagalactic space; but much work needs to be done before sequences accurate to one- or two-tenths of a magnitude can be obtained from star-counts, especially in the southern hemisphere and in galactic longitudes less than $\pm 20^{\circ}$.

It is proposed by Madwar that the problem of establishing nebular magnitude sequences independent of stellar magnitude sequences be brought up for discussion at the Paris meeting.

Dr Wirtz of Kiel has in the past paid much attention to the problems of surface brightness, of both galactic and extragalactic nebulae. He notes that we have not yet at our command sufficiently accurate material for the proper examination of these problems. He writes:

(a) Die echten Spiralnebel und die strukturlosen (elliptischen oder Kugel-) Nebel zeigten bei mehreren Untersuchungen in der statistischen Korrelation nach Flächenhelligkeit und scheinbaren Durchmesser grundsätzliche Verschiedenheit. Die struktur- 
losen Nebel ordnen sich in dieser Hinsicht zudem den kugelförmigen Sternhaufen an. Es wäre wünschenswert, wenn zu näherem Studium dieser Verhältnisse photometrische Messungen der Flächenhelligkeiten von Spiral- und Kugelnebeln verbunden würden mit genaueren Bestimmungen des scheinbaren Durchmessers der Objekte oder eines anderen Maasses des Abstandes. Dieselben Betrachtungen wären auf die Kugelhaufen anzudehnen. Es ist nicht schwer, in zwei Farbgebieten zu arbeiten.

(b) Ein gleiches gilt von den planetarischen Nebeln. Auch hier verrät sich in Flächenhelligkeit und scheinbaren Durchmesser (Entfernung !) eine überraschende Korrelation, die durch genaue Beobachtung beider Elemente gesichert (oder widerlegt) werden sollte. $\mathrm{Zu}$ den Durchmesserbestimmungen hier wie dort lässt sich die photometrische Vermessung der Randzonen (in beliebiger Form) heranziehen. Und man wird erwägen, ob nicht bei geringer Anzahl weit voneinander entfernter Objekte (planetarische Nebel) die visuelle Bestimmung der Flächenhelligkeiten nicht nur ökonomischer, sondern auch genauer ist.

4. Too little systematic work has been done as yet on the colours of external galaxies. Dr Carpenter at Tucson and Dr Whipple at Harvard are carrying on investigations of the distribution of colour throughout some of the brighter objects; and Dr Vanderlinden at Bruxelles is investigating the effective wave-length of some three hundred condensations in the arms of the spiral Messier 5I. Dr Vanderlinden is also working on the effective wave-lengths of the nuclei of planetary nebulae, and has completed similar studies of the galactic clusters Praesepe and Messier 67.

The studies of the colours of galactic stars need further extension because of the importance of absorption in the problems of galactic structure and dimensions. Notable contributions in this field have been made by Stebbins and Huffer (photoelectric), Schalén (photographic), and others.

5. The use of a densitometer with photographic plates has of late considerably changed our technique and our knowledge of the diameters of external galaxies. Much further work is necessary not only on the measurement of the diameters of faint and distant galaxies, but also on the detailed structure of the larger systems. It appears that rapid, small-scale cameras are very satisfactory for this work except in low galactic latitudes, where the rich star fields interfere.

6. The recent work on globular clusters includes significant contributions from Mount Wilson (Baade, Stebbins), Victoria (Mrs Hogg), McCormick (Vyssotsky, Williams), Harvard (Mohr, Shapley, Sayer), and the publication of the positions of individual stars by Schlesinger, using plates made at the Yerkes Observatory. None of these investigations calls for special attention by the Commission; but the investigation of galactic clusters, their distances, dimensions, and internal structure, deserves more widespread attention. The contributions of Wallenquist (Bosscha Observatory), Bernheimer (Vienna), Mrs Rieke (Harvard), and Trumpler and associates (Lick Observatory) serve to illustrate the importance of the problems involved. Further consideration of the absolute magnitude criteria from various standpoints is urgent. The spectral classes and provisional absolute magnitudes for 2700 stars in fifty-fotur galactic clusters are being reported by Mrs Rieke in a current publication (Harvard Circular, 397, I935). Dr Trumpler calls attention to problems that involve the galactic clusters in relation to other fields of astronomy:

I should like to suggest the relation between studies on the motions of star clusters and nebulae and the general problem of galactic rotation. It seems to me that the radial velocity observations of planetary and diffuse galactic nebulae as well as of galactic star 
clusters are destined to make important contributions to the problems of galactic rotation, and that proper motions of extragalactic nebulae (measured relatively to faint stars) should be helpful for finding the general rotation of our galactic system.

In this same connection, Dr Wirtz of Kiel recommends:

Auswahl geeigneter Spiralnebel mit scharfem Kern zur genauen Ortsbestimmung. Ziel: Fixierung eines absoluten Skeletts für die Ortsbestimmung der Fixsterne, als Bezugssystem der Sternörter. Es ist leicht möglich einen Katalog von 500 solcher Objekte aufzustellen, die erträglich über die Sphäre verteilt sind. Wenn man hierbei die von H. Schultz visuell ausgezeichnet beobachteten Nebel (Upsala, 1863-74) besonders berücksichtigen möchte, so in der Erwartung, dass sie zur Verschärfung der Orter in ähnlicher Weise beitragen, wie das heute etwa bei Lalandes Beobachtungen für Sternörter der Fall ist. Das trifft zu; denn auch die Schultz'schen Nebelörter haben nur mehr eine historische Bedeutung (allerdings als sehr wichtige Stufe der Erkenntnis).

In das Netz der Sterne sollen diese Nebel, die fürderhin unser absolutes "Fundamental "-System repräsentieren, durch Weitwinkelkameras hineinprojiziert werden, wie sie sich in den Zonen der Yale Sternwarte (F. Schlesinger) so glänzend bewährt haben. Viele dieser Nebel sind auf den Yale-Platten schon vorhanden und brauchen nur nachgemessen zu werden. Doch mag es besser sein, an diese wichtige Aufgabe mit etwas längerer Brennweite heranzugehen; 3 Meter würde mehr als genügen.... Das ist aber schon Angelegenheit der Kommission 8 (Meridianastronomie)....

7. Investigations of planetary nebulae include: the measurement of the proper motions of twenty-one objects by van Maanen (Mount Wilson Contribution, 463, I933) and of thirty-three by Anderson (L.O.B. I7, 2I, I934); a number of important theoretical considerations on the structure and the radiation of planetary nebulae; and conspicuous advance in the identification of their spectral lines. Much is to be done in the ultra-violet and the infra-red regions; and attention is called to the need of much more detailed spectrophotometry both of line profiles and of background intensity before completely satisfactory interpretations will be possible for the widely differing objects that are brought together under the general term of planetary nebulae.

8. The problems of obscuring matter in the Milky Way and of nebulosity everywhere connect at once with the problems of stellar statistics. Important contributions in knowledge of dark nebulae and space absorption have been published from Stockholm, Lyon, Lick, Harvard, Potsdam, and elsewhere, and the Roberts Prize has rewarded and inspired investigations in this field. The members of the Commission are happy to acknowledge the important service to astronomy that has been thus provided through the generosity of Madame Roberts.

9. Various theoretical considerations of the structure of galaxies and of the Metagalaxy during recent years point the way to and the need of further investigations. Of most importance are the various contributions by Lindblad on the development of large stellar systems, and of de Sitter, Milne, McVittie, Lemaitre, and Robertson on problems of world structure. The observational basis for the expanding universe hypothesis has been greatly extended by the work of Hubble and Humason at Mount Wilson; to assist in meeting the urgent need for nebular radial velocities for the southernmost quarter of the sky, the Harvard Observatory has recently procured a high-speed Rayton camera lens for use with the Hilger spectrograph on the 6o-inch reflector at the Bloemfontein Station.

IO. It is recommended that at the first meeting of the Commission in Paris the question be raised whether it would not be profitable to arrange a joint meeting with 
Commission 33, Stellar Statistics, and another with Commission 36, Spectrophotometry, to discuss problems of mutual interest to the two Commissions. With Commission 33 the common problems of the distribution of dark nebulosity in low latitudes and the revision and extension of the Seares and van Rhijn tables might be appropriately considered; and with Commission 36 the problems of energy distribution in external galaxies, as well as the problems of the constitution of planetary and diffuse nebulae, should awaken a common interest.

Dr Lundmark has written the following report of the work on clusters and nebulae at the Lund Observatory:

The work as to the preparation of a new general catalogue of nebulae and clusters (L.G.C.) is divided into three parts:

I. Collection of the data.

2. Making the data homogeneous.

3. Statistical discussion of the homogenized data.

The collection of the data embraces all published sources and a number of unpublished. If all objects so far observed should be included in the catalogue then it would contain at least 50,000 objects. But the proposition to restrict the catalogue to all objects brighter than a certain limiting magnitude, say $15^{\mathrm{m} \cdot 5}$, is also under careful consideration.

The making of the material homogeneous has also been started. Two of the older and more extensive catalogues, the ones by Bigourdan (about 5000 objects) and d'Arrest (about 2000 objects) have been evaluated in such a way that the traditional descriptions have been translated into numerical symbols, which have been correlated with modern measurements and estimates. In the delicate task of translating statistically the catalogue of d'Arrest, written in Latin, I have had most efficient help from Dr P. Collinder. The general results from these two catalogues will emphasize the conclusion as to the high value of the visual material as giving data for nebulae and clusters.

In parallel with the work for preparing a new general catalogue numerous investigations as to the distances and properties of the nearby galaxies have also been carried on. The absolute magnitudes of Milky Way Novae have been rediscussed and the zero-point for the Cepheids has also been redetermined. For that purpose proper motions of some Iro Cepheids have been derived, using all existing material (also C.d.C.-catalogues). In this material are included a score of Boss stars, the p.m.'s of which should be materially improved through the inclusion of modern catalogues. The results are not definite but a discussion of proper motions and radial velocity data substantiates the value of the zero-point derived by Shapley. To this value should be added a correction of $-0^{\mathrm{m} .85}$, or so, on account of a possible absorption in the galactic zone. It seems that the distance of the Andromeda nebula will be of the order of magnitude of $1.4 \cdot 10^{6}$ light years.

The catalogue is intended to contain two parts: $r$, an index catalogue attributing to each object one entry and containing the data which have resulted from the final statistical discussion; and 2, a source catalogue which shall in a kind of encyclopaedic form give a summary of all our knowledge concerning the individual objects. The work will begin with an introductory volume giving the historical development of our knowledge as to nebulae and clusters.

\section{HARLOW SHAPLEY \\ President of the Commission.}

